\title{
Social media addiction and sexual dysfunction among Iranian women: The mediating role of intimacy and social support
}

\author{
ZAINAB ALIMORADI ${ }^{1}$, CHUNG-YING LIN ${ }^{2}$, VIDA IMANI ${ }^{3}$, MARK D. GRIFFITHS $^{4}$ and AMIR H. PAKPOUR ${ }^{1,5 *}$ \\ ${ }^{1}$ Social Determinants of Health Research Center, Qazvin University of Medical Sciences, Qazvin, Iran \\ ${ }^{2}$ Department of Rehabilitation Sciences, The Hong Kong Polytechnic University, Hung Hom, Hong Kong \\ ${ }^{3}$ Pediatric Health Research Center, Tabriz University of Medical Sciences, Tabriz, Iran \\ ${ }^{4}$ International Gaming Research Unit, Psychology Department, Nottingham Trent University, Nottingham, UK \\ ${ }^{5}$ Department of Nursing, School of Health and Welfare, Jönköping University, Jönköping, Sweden
}

(Received: January 19, 2019; revised manuscript received: March 14, 2019; accepted: April 7, 2019)

\begin{abstract}
Background and aims: Social media use has become increasingly popular among Internet users. Given the widespread use of social media on smartphones, there is an increasing need for research examining the impact of the use of such technologies on sexual relationships and their constructs such as intimacy, satisfaction, and sexual function. However, little is known about the underlying mechanism why social media addiction impacts on sexual distress. This study investigated whether two constructs (intimacy and perceived social support) were mediators in the association of social media addiction and sexual distress among married women. Methods: A prospective study was conducted where all participants $(N=938$; mean age $=36.5$ years $)$ completed the Bergen Social Media Addiction Scale to assess social media addiction, the Female Sexual Distress Scale - Revised to assess sexual distress, the Unidimensional Relationship Closeness Scale to assess intimacy, and the Multidimensional Scale of Perceived Social Support to assess perceived social support. Results: The results showed that social media addiction had direct and indirect (via intimacy and perceived social support) effects on sexual function and sexual distress. Discussion and conclusions: The findings of this study facilitate a better understanding of how problematic engaging to social media can affect couples' intimacy, perceived social support, and constructs of sexual function. Consequently, sexual counseling should be considered an essential element for assessing individual behaviors in the context of social media use.
\end{abstract}

Keywords: social media addiction, sexual function, intimacy, social support

\section{INTRODUCTION}

The rapid growth in communication and information technologies has made it increasingly easier to access Internet worldwide. In 2017, approximately 3.77 billion people of the world's population accessed the Internet through their own smartphones or computers (Anand, Brandwood, \& Jameson Evans, 2017). The penetration rate of Internet use among young people aged 15-24 years has been estimated to be $94 \%$ in developed countries and $67 \%$ in developing countries (International Telecommunication Union, 2017). According to a recent report, $69.1 \%$ of the Iranian population (where this study was carried out) were Internet users at the beginning of 2018 (Internet World Stats, 2018).

In recent years, social media has become an integral part of individuals' daily lives (Masthi, Pruthvi, \& Phaneendra, 2018). The extent of social media penetration is continuing to increase all over the world. In $2017,71 \%$ of Internet users were social network users (Statista, 2018). The number of social media users has increased from less than 1 billion in 2010 to 2.46 billion in 2017 (Pakpour, Yekaninejad, Pallich, $\&$ Burri, 2015). Furthermore, the number of social media users is expected to reach to more than 3 billion people in 2021 (Statista, 2018). In Iran, approximately 40 million individuals are active social media users, which represents $135 \%$ increase on the year before. The growth in social media use in Iran is ranked fourth in the world after China, India, and Indonesia (Financial Tribune, 2018). According to one statistics website, $64.86 \%$ of Iranian social network users were active on the Facebook in 2018 (StatCounter, 2018).

While Internet addiction (IA) is rarely observed in individuals, being engaged in online activities through Internet-based media such as online games and social networks can lead to addictive behaviors in a small minority of users (Griffiths, 2017). The addictive use of social networks is a specific form of "technological addiction" and has similarities with Internet gaming disorder, which was tentatively included in the latest (fifth) edition of the Diagnostic

\footnotetext{
* Corresponding author: Assoc. Prof. Amir H. Pakpour, PhD; Social Determinants of Health Research Center, Qazvin University of Medical Sciences, Shahid Bahounar BLV, Qazvin 3419759811, Iran; Phone/Fax: +98 28 33239259; E-mail: Pakpour_Amir@ yahoo.com; apakpour@qums.ac.ir
}

This is an open-access article distributed under the terms of the Creative Commons Attribution-NonCommercial 4.0 International License, which permits unrestricted use, distribution, and reproduction in any medium for non-commercial purposes, provided the original author and source are credited, a link to the CC License is provided, and changes - if any - are indicated. 
and Statistical Manual of Mental Disorders as a disorder that requires further research (American Psychiatry Association [APA], 2013). These conditions have been argued to have similar symptoms of addiction including salience, mood modification, tolerance, withdrawal, conflict, and relapse (He, Turel, \& Bechara, 2017). Social media addiction is characterized by paying excessive attention to social media activities often to the neglect of all other activities, and uncontrollable use to the extent that it interferes with other important areas of life including personal relationships, education, and/or occupation to the detriment of the individual (i.e., clinical impairment; Dong \& Potenza, 2014). Therefore, technological addictions such as social media addiction can have negative and severe psychological and psychosocial impacts (Griffiths, 2000). The excessive online use is typically accompanied by a reduction in the size of the individuals' social circle, as well as an increase in loneliness and depression (Lin et al., 2018). The results of the study by Yao and Zhong (2014) using a prospective study confirmed that excessive and unhealthy use of the Internet over time increased the sense of loneliness among male and female students (aged: 18-36 years). Although depression had a positive and bidirectional mediating effect with IA, such a relationship was not reported in the crosslagged analysis. They reported that online social relationships with friends and family were not an effective substitute for offline interactions in reducing loneliness.

Problems encountered by individuals in relation to online use and Internet-based media should be examined more carefully from the following perspectives: (a) how individuals use this space to develop their relationships and (b) how much time individuals spend communicating with others (Whitty, 2008). Spending a lot of time and energy on Internet-related activities can affect many aspects of the individual's life (Dong \& Potenza, 2014). Different studies have shown that sexual health is one of the individual health areas that may be influenced by IA and/or Internet-related activities (Felmlee, 2001; Whitty, 2008; Zheng \& Zheng, 2014). As the number of Internet users has increased, so has the number of individuals who use the Internet for sexual activities (Cooper \& Griffin-Shelley, 2002). Words related to "sex" are the top terms used in search engines as evidence for this claim (Goodson, McCormick, \& Evans, 2001). Online sexual activities refer to any kind of online sexual activity such as searching for sexual partners, buying sexual products, sexual conversations, accessing and watching pornography, and having cybersex (Cooper \& GriffinShelley, 2002). The use of online sexual content can play a significant role in committed relationships between spouses (Olmstead, Negash, Pasley, \& Fincham, 2013). In a study of heterosexual couples by Bridges and Morokoff (2011), 48.4\% of men and $64.5 \%$ of women in the sample indicated that the use of sexual content is part of lovemaking with their partners. Although looking for online sexual content can create positive experiences for individuals, the excessive use of the Internet for sexual purposes can be disordered and/or addictive (Daneback, Ross, \& Månsson, 2006). Studies by Aydın, Sarı, and Şahin (2018) and Eichenberg, Huss, and Küsel (2017) demonstrated that addiction to cybersex can be a contributing factor to couples' separation and divorce. In addition, cybersex users reported a decline in their desire for sexual intercourse. Muusses, Kerkhof, and Finkenauer (2015) examined the short-term and long-term relationships between the use of online sexual content and quality of spousal relationships and found a negative and reciprocal association between the use of sexual content and relationship adjustment among husbands. In other words, male sexual satisfaction with their partners predicted a decline in the use of online sexual content among husbands over the next year. However, the use of online sexual content by women did not affect sexual satisfaction with their spouses.

Sexual relationships and relationship satisfaction depend on the extent to which partners understand the needs and desires of each other (Peleg, 2008). Relationship adjustment is an evolutionary process between two people, which is influenced by interpersonal communication skills and the quality of sexual relationships (Sinha \& Mukerjee, 1990). Interpersonal interactions are one of the most important predictors of relationship satisfaction. Sexual relationships are satisfactory for both parties not only when there is the physical presence, but also a connection between sexual partners (Roberts \& David, 2016). Satisfaction with the relationship, agreement, coherence, and expression of emotions and sexual satisfaction are structures that affect the quality of romantic partnerships (Muusses et al., 2015). Failure to establish a desirable sexual relationship and dissatisfaction with it can be accompanied by a reduction in happiness, life satisfaction, depression, anxiety, obsession and compulsion, loneliness, emptiness, low self-esteem, and mental disorders. It can also lead to difficulties in performing parental duties (Barzoki, Seyedroghani, \& Azadarmaki, 2013; Heiman et al., 2011; McNulty, Wenner, \& Fisher, 2016). Schmiedeberg and Schröder (2016) showed that the length of relationship is associated with sexual satisfaction, health status, and intimacy in the relationship, whereas conflict styles can affect sexual satisfaction with partners.

Given the widespread use of smartphones and installing different applications and connection to the Internet and social networks (Hertlein, 2012; Luo \& Tuney, 2015), there is an increasing need for research examining the impact of the use of such technologies on sexual relationships and their constructs, such as intimacy, satisfaction, and sexual function. Since prospective studies can demonstrate a stronger relationship between variables and considering the importance of such a relationship between online social networks and the quality of marital relationship, this study assessed the impact of social media use on couples' sexual health including sexual function, sexuality, and intimacy of couples over time.

\section{METHODS}

\section{Participants}

The present research was a prospective study in women referred to urban health centers receiving routine health care in the Iranian city of Qazvin between August 2017 and October 2018. In Iran, the health system works through a network. This network comprises a referral system, beginning from primary care centers in the periphery to tertiary 
hospitals in major cities. The city of Qazvin has 12 urban health centers that offer a variety of care services including prenatal care, pregnancy, postpartum, child growth monitoring, vaccination, and midwifery care services. These urban health centers are affiliated to Qazvin University of Medical Sciences, and family health records are maintained in these centers.

Female participants were included based on the eligibility criteria of being 18 years of age or older, being married or sexually active within the past 6 months, and willingness to participate in the study. Exclusion criteria were (a) having chronic physical illnesses (e.g., diabetes mellitus and cardiovascular diseases) or severe psychological illnesses, (b) using drugs that affect sexual function (e.g., psychiatric drugs and antihypertensive drugs), and (c) pregnant and lactating women. Following this recruitment process, 938 married women participated in this study.

\section{Measures}

The studied variables in this study included social media addiction, female sexual function, female sexual distress, intimacy and relationship closeness, social support, anxiety, and depression. In addition, demographic variables including age, education level of the woman and her husband, employment status, duration of marriage, frequency of sexual intercourse per month, pregnancy history, body mass index, women's fertility status, and smoking were studied.

Addiction to social media was assessed using the Bergen Social Media Addiction Scale (BSMAS; Andreassen et al., 2016). The BSMAS comprises six items on a 5-point Likert scale from 1 (very rarely) to 5 (very often). The BSMAS includes six core components of addiction (i.e., salience, mood modification, tolerance, withdrawal, conflict, and relapse). Higher scores on the BSMAS relate to a more severe addiction to social media use, and a score above 19 indicates that the individual is at risk of being addicted to social media use (Bányai et al., 2017). The scale was translated into Farsi with verified validity and reliability (Lin, Broström, Nilsen, Griffiths, \& Pakpour, 2017). Cronbach's $\alpha$ of the BSMAS in this study was .84 .

Female sexual function was assessed using the Female Sexual Function Index (FSFI; Lin, Burri, Fridlund, \& Pakpour, 2017; Lin, Oveisi, Burri, \& Pakpour, 2017; Rosen et al., 2000). It assesses sexual function in women using 19 questions comprising six independent areas, including desire (2 questions), psychological stimulation (4 questions), lubrication (4 questions), orgasms (3 questions), satisfaction (3 questions), and sexual pain (3 questions). The psychometric properties of the Farsi version of the FSFI were found to be satisfactory (Fakhri, Pakpour, Burri, Morshedi, \& Zeidi, 2012). Cronbach's $\alpha$ of the FSFI in this study was .87 .

Female sexual distress was assessed using the Female Sexual Distress Scale - Revised (FSDS-R). This is a selfreport scale with 13 items that examine various aspects of women's sexual activities. All questions have a 5-point Likert score from 0 (never) to 4 (always). The higher the score, the more the sexual distress. The overall score is obtained by the summation of each question score (DeRogatis, Clayton, Lewis-D'Agostino, Wunderlich, \& Fu, 2008). Validity and reliability of its Farsi version was confirmed (Azimi Nekoo et al., 2014). Cronbach's $\alpha$ of the FSDS-R in this study was .81 .

Intimacy was assessed using the Unidimensional Relationship Closeness Scale (URCS). The URCS is a selfreport scale comprising 12 items that assess the degree of closeness in individuals and social relationships (Dibble, Levine, \& Park, 2012). The results of the URCS survey in different groups (college dating couples, female friends and strangers, friends, and family members) showed that it had an appropriate validity and reliability (Dibble et al., 2012). In this study, the URCS was translated into Farsi according to the international standard translation guidelines (Pakpour, Zeidi, Yekaninejad, \& Burri, 2014). Accordingly, the test-retest reliability of the Farsi URCS was 0.91 within a 2-week interval and Cronbach's $\alpha$ coefficient was .88 . Moreover, the unidimensional structure of the URCS was confirmed.

Social support was assessed using the Multidimensional Scale of Perceived Social Support (MSPSS; Zimet, Dahlem, Zimet, \& Farley, 1988). This scale has 12 items on a 5-point scale from grade 1 (completely disagree) to 5 (completely agree). The minimum and maximum scores are 12 and 60, respectively. Psychometric properties of the Farsi MSPSS were verified by Salimi, Joukar, and Nikpour (2009). Cronbach's $\alpha$ of the MSPSS in this study was .93 .

Anxiety and depression were assessed using the Hospital Anxiety and Depression Scale (HADS; Zigmond \& Snaith, 1983). This scale comprises 14 questions in two subscales of anxiety and depression on a 4-point Likert scale from 0 to 3. The maximum score on each subscale is 21 . Scores above 11 on each subscale indicate psychological illness, scores of 8-10 represent borderline cases, and scores of $0-7$ are considered normal. Psychometric properties of the Farsi HADS were confirmed by Montazeri, Vahdaninia, Ebrahimi, and Jarvandi (2003) and Lin and Pakpour (2017). Cronbach's $\alpha$ of the HADS in this study was 90 .

\section{Procedure}

A multistage cluster random-sampling method was applied. To achieve a maximum variation and economic and social diversity, the research team contacted all urban health centers in Qazvin city. After obtaining permissions, the researchers contacted eligible participants and invited them to participate in the study. One hundred files were randomly selected and screened for inclusion criteria in a telephone interview. Those women who met inclusion/exclusion criteria were asked to complete the study measures at baseline in a session in the urban health centers. The participants were then followed for a 6-month period. Six months later, the same women were asked to complete the sexual function, sexual distress, and anxiety and depression scales for the second time.

\section{Statistical analyses}

Continuous data were expressed as means [standard deviation $(S D)$ ] and categorical data were expressed using numbers and frequency percentages. Zero-order correlations were conducted to determine the bivariate relationships 
between study variables, including baseline and follow-up measures. Mediation analysis was conducted to test whether the effects of social media addiction on sexual functioning/ sexual distress were mediated by perceived social support and relationship closeness using bootstrapping methods. Therefore, two mediation models were performed (i.e., Model A used FSFI as outcome measure and Model B used FSDS-R as outcome measure). In each model, the following relationships were tested: (a) the BSMAS effect on FSFI or FSDS-R (path "c" in Figure 1), (b) the BSMAS effect on mediators (i.e., perceived social support and relationship closeness; paths " $a_{1}$ " and " $a_{2}$ " in Figure 1), and (iii) mediator effects (perceived social support and relationship closeness) on FSFI or FSDS-R (paths " $b_{1}$ " and " $\mathrm{b}_{2}$ " in Figure 1). In addition, the three-step recommendations from Krull and MacKinnon (1999) were used to tackle the impact of the clustered data. Finally, age, husband's education, depression, anxiety, FSFI, and FSDS-R at baseline were adjusted for both Models A and B.

PROCESS macro in SPSS (Hayes, 2013; Model 4) was used to perform multiple mediation analysis. A bootstrap procedure of 10,000 replications was used to evaluate the significance of the indirect effects. The absence of zero in the $95 \%$ bias-corrected and accelerated confidence interval (CI) is needed to identify mediated effects. The statistical analyses were performed using SPSS version 24 (IBM, Armonk, NY, USA) with significance level set at $\alpha=.05$.

\section{Ethics}

The research proposal was approved by the Ethics Committee for Biological Research in the Qazvin University of Medical Sciences. Permissions for sampling were obtained from relevant authorities. Before data collection, all ethical considerations including description of the study, privacy and confidentiality of data, anonymity, freedom to participate in the study, and withdrawal from the study were considered and explained. In addition, a written informed consent form was signed by all participants.

\section{RESULTS}

The participants $(n=938)$ had a mean age of 36.5 years $(S D=6.8)$. The mean year of education was 11.7 years for

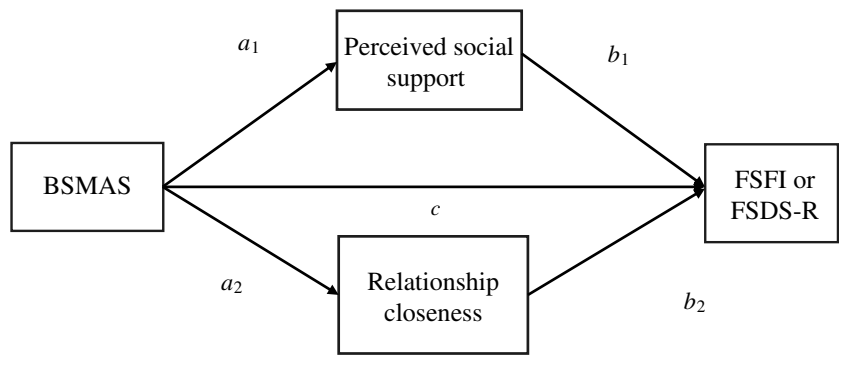

Figure 1. The hypothesized mediation models with perceived social support and relationship closeness as proposed mediators of the effect of social media addiction on sexual function, sexual distress, depression, and anxiety. BSMAS: Bergen Social Media Addiction Scale; FSFI: Female Sexual Function Index; FSDS-R: Female Sexual Distress Scale - Revised participants and 12.24 years for their husbands. The mean marriage duration was 9.7 years. More than half of them were housewives and $88 \%$ of them were in the premenopausal age. In addition, $36 \%$ of them had a pregnancy history.

The mean scores on each scale were as follows: social media addiction $=15.6$ (out of 30 ), perceived social support $=53.2$ (out of 60), intimacy $=4.9$ (out of 7), sexual function $=27.7$ (out of 95), anxiety $=7.7$ (out of 21), depression $=6.2$ (out of 21), and sexual distress $=7.4$ (out of 52). After a 6-month period, the mean scores of anxiety and depression increased slightly and the mean score of sexual function and sexual distress decreased slightly. Table 1 shows the demographics, means, and $S D$ s at the baseline and after 6 months.

Table 2 presents the results of zero-order correlation analysis between MSPSS, BSMAS, FSFI (at baseline and follow-up), anxiety (at baseline and follow-up), depression (at baseline and follow-up), FSDS-R (at baseline and follow-up), and URCS. The results showed that FSFI at 6 months was positively correlated with MSPSS and URCS, but negatively correlated with anxiety, and depression at 6 months, and social media addiction.

The degree to which perceived social support and relationship closeness mediated the relationship between social medial addiction and sexual functioning (Model A)/sexual distress (Model B) was tested. The results based on 10,000 bias-corrected bootstrapped samples indicated that the total effect of social media addiction on FSFI was significant $(B=-0.93, p<.001)$, with URCS and MSPSS explaining $31.3 \%$ of the relationship between social media addiction and FSFI. There was an indirect effect of social media addiction on FSFI via URCS: $B=-0.16, S E=0.05,95 \%$ $\mathrm{CI}=[-0.29,-0.09]$. There was also indirect effect via MSPSS: $B=-0.11, S E=0.03,95 \% \mathrm{CI}=[-0.19,-0.06]$ (Table 3; Model A).

In Model B (Table 3), the total indirect effect of social media addiction on FSDS-R was also statistically significant $(B=1.23, p<.001)$, with URCS and MSPSS explaining $45.6 \%$ of the relationship between social media addiction and FSDS-R. Regarding specific indirect effects, both URCS $(B=0.38, S E=0.10,95 \% \mathrm{CI}=0.24,0.62)$ and MSPSS $(B=0.26, S E=0.08,95 \% \mathrm{CI}=0.15,0.46)$ were significant mediators between social media addiction and FSDS-R.

\section{DISCUSSION}

This is the first study to investigate the effect of social media addiction on women's sexual function, taking into account the mediating role of social and civic support in the marital relationship using a prospective longitudinal study within a 6-month time interval. McNulty et al. (2016) in a longitudinal study of 207 couples in the first 4-5 years of marriage reported that over time, marital satisfaction, sexual satisfaction, and the frequency of sexual relationships in couples decreased. Feelings of love, marital conflicts, and marital satisfaction can affect sexual satisfaction, which plays an important role in women's sexual function (Pakpour et al., 2015).

Anxiety and depression are psychological conditions that affect women's sexual function (Burri, Rahman, \& 
Table 1. Participants' characteristics $(N=938)$

\begin{tabular}{lc}
\hline Characteristics & $n(\%)$ or $M(S D)$ \\
\hline Baseline & \\
Age (years) & $36.5(6.8)$ \\
Years of education & $11.7(4.8)$ \\
Number of years' education (husband) & $12.24(5.9)$ \\
Duration of marriage (years) & $9.7(6.4)$ \\
Coital frequency (per month) & $5.2(3.9)$ \\
Current smoker & $137(14.6 \%)$ \\
Occupational status & \\
Unemployed & $677(55.3 \%)$ \\
Employed & $261(23.0 \%)$ \\
Student & $158(16.8 \%)$ \\
Menopausal status & \\
Postmenopause & $113(12.0 \%)$ \\
Premenopause & $825(88.0 \%)$ \\
Parity & \\
0 & $315(33.6 \%)$ \\
1 & $341(36.3 \%)$ \\
2 & $209(22.3 \%)$ \\
$\geq 3$ & $73(7.8 \%)$ \\
BMI (kg/m²) & $22.9(6.2)$ \\
Baseline & \\
Social media addiction & $15.6(5.8)$ \\
Perceived social support & $53.2(10.7)$ \\
Relationship closeness & $4.9(0.9)$ \\
Sexual functioning & $27.7(4.6)$ \\
Anxiety & $7.7(4.9)$ \\
Depression & $6.2(4.8)$ \\
Female sexual distress & $7.4(3.7)$ \\
Six months after baseline & \\
Sexual functioning & $27.0(4.9)$ \\
Anxiety & $7.9(4.7)$ \\
Depression & $6.4(4.5)$ \\
Female sexual distress & $7.3(3.4)$ \\
\hline
\end{tabular}

Note. SD: standard deviation; BMI: body mass index.

Spector, 2011; Johannes et al., 2009; Johnson, Phelps, \& Cottler, 2004; Serati et al., 2010). The results of this study showed that female sexual dysfunction was associated with depression and anxiety. Consequently, online engagement with social media was another factor that contributed to low female sexual dysfunction in this study. These results are consistent with those of previous research on the impact of social media activity on sexual performance. Zheng and Zheng (2014) found that the quality of sexual relationships of individuals was affected by online activities and the use of online sexual content. They reported that one of the predictors of online sexual activity was sexual sensation seeking. They found that the shift from actual sexual behavior to virtual sexual behavior was due to the tendency to have new and exciting sexual experiences. Sexual desire, attitude, and behavior were positively and significantly correlated with using online sexual materials. The negative impact of the use of online sexual content on sexual compatibility and sexual satisfaction has also been observed by Muusses et al. (2015). They showed that the use of online sexual content by men had a significant and reverse association with their sexual compatibility and satisfaction. Although the use of online sexual content can create positive experiences for some individuals (Bridges \& Morokoff, 2011), Eichenberg et al. (2017) and Aydin et al. (2018) showed that users with online sexual activities in the cyberspace were reluctant to have real sexual relationships. Because sexual dysfunction can be due to disturbances in tendency, arousal, orgasm, and sexual pain (APA, 2013), the loss of sexual desire can be associated with female sexual dysfunction.

Although the results of this study report the impact of the use of social media on sexual performance, the difference between this study and previous studies is that social media addiction was explored in this study, which did not necessarily include the use of sexual content. In contemporary society, given the increasing reach of the Internet, problematic Internet use and online-based media are not only related to its content, but are also related to the time spent using these media and how interpersonal relationships develop (Whitty, 2008). Spending time and energy on Internet-based activities can affect many aspects of an individual's life (Dong \& Potenza, 2014). McDaniel and Coyne (2016) found that the use of such technologies interfere with the relationship between romance and satisfaction within relationships. Such an effect in this study was investigated by examining the role of intimacy and perceived social support as mediators. More specifically, this study showed that social support and intimacy accounted for a significant

Table 2. Zero-order correlations for sexual function, anxiety, depression, social media addiction, relationship closeness, and sexual distress

\begin{tabular}{lcccccrrrrr}
\hline & BSMAS $^{\mathrm{a}}$ & FSFI $^{\mathrm{a}}$ & Anxiety $^{\mathrm{a}}$ & Depression $^{\mathrm{a}}$ & FSDS-R $^{\mathrm{a}}$ & URCS $^{\mathrm{a}}$ & FSFI $^{\mathrm{b}}$ & Anxiety $^{\mathrm{b}}$ & Depression $^{\mathrm{b}}$ & FSDS-R $^{\mathrm{b}}$ \\
\hline MSPSS $^{\mathrm{a}}$ & -0.14 & 0.21 & -0.24 & -0.34 & -0.40 & 0.28 & 0.24 & -0.21 & -0.30 & -0.43 \\
BSMAS $^{\mathrm{a}}$ & - & -0.22 & 0.29 & 0.45 & 0.25 & -0.27 & -0.28 & 0.33 & 0.44 & 0.32 \\
FSFI $^{\mathrm{a}}$ & - & - & -0.29 & -0.37 & -0.32 & 0.20 & 0.58 & -0.37 & -0.40 & -0.38 \\
Anxiety $^{\mathrm{a}}$ & - & - & - & 0.51 & 0.48 & -0.38 & -0.41 & 0.55 & 0.50 & 0.48 \\
Depression $^{\mathrm{a}}$ & - & - & - & - & 0.49 & -0.21 & -0.48 & 0.44 & 0.56 & 0.69 \\
FSDS-R $^{\mathrm{a}}$ & - & - & - & - & - & -0.26 & -0.49 & 0.50 & 0.44 & 0.54 \\
URCS $^{\mathrm{a}}$ & - & - & - & - & - & - & 0.27 & -0.31 & -0.28 & -0.33 \\
FSFI $^{\mathrm{b}}$ & - & - & - & - & - & - & - & -0.41 & -0.39 & 0.51 \\
Anxiety $^{\mathrm{b}}$ & - & - & - & - & - & - & - & - & 0.40 & 0.37 \\
Depression $^{\mathrm{b}}$ & - & - & - & - & - & - & - & - & - & 0.35 \\
\hline
\end{tabular}

Note. MSPSS: Multidimensional Scale of Perceived Social Support; BSMAS: Bergen Social Media Addiction Scale; FSFI: Female Sexual Function Index; FSDS-R: Female Sexual Distress Scale - Revised; URCS: Unidimensional Relationship Closeness Scale. All $p$ values $<.01$. ${ }^{\mathrm{a}}$ Assessed at 6 months. ${ }^{\mathrm{b}}$ Assessed at baseline. 
Table 3. Models of the effect of women's social media addiction on sexual function, sexual distress, and psychological distress with mediators of perceived social support and relationship closeness

\begin{tabular}{|c|c|c|c|c|}
\hline & Coefficient & $S E$ & $t$ & $p$ \\
\hline \multicolumn{5}{|l|}{ Model A. Outcome variable: FSFI } \\
\hline Total effect of BSMAS on FSFI & -0.93 & 0.14 & 6.83 & $<.001$ \\
\hline \multicolumn{5}{|c|}{ Effects of BSMAS on FSFI in mediated model } \\
\hline \multicolumn{5}{|c|}{ Direct effect of BSMAS on mediator ${ }^{\mathrm{a}}$} \\
\hline URCS & -0.39 & 0.04 & -8.54 & $<.001$ \\
\hline MSPSS & -0.25 & 0.06 & -4.37 & .003 \\
\hline Direct effect of BSMAS on FSFI & -0.67 & 0.14 & -4.77 & $<.001$ \\
\hline Indirect effect of BSMAS on FSFI & Effect & Boot SE & Boot LLCI & Boot ULCI \\
\hline Total & -0.27 & 0.07 & -0.44 & -.16 \\
\hline URCS & -0.16 & 0.05 & -0.29 & -.09 \\
\hline MSPSS & -0.11 & 0.03 & -0.19 & -.06 \\
\hline \multicolumn{5}{|l|}{ Model B. Outcome variable: FSDS-R } \\
\hline Total effect of BSMAS on FSDS-R & 1.23 & 0.15 & 7.94 & $<.001$ \\
\hline \multicolumn{5}{|c|}{ Effects of BSMAS on FSDS-R in mediated model } \\
\hline \multicolumn{5}{|c|}{ Direct effect of BSMAS on mediator ${ }^{\mathrm{a}}$} \\
\hline URCS & -0.38 & 0.05 & -8.42 & $<.001$ \\
\hline MSPSS & -0.24 & 0.06 & -4.18 & $<.001$ \\
\hline Direct effect of BSMAS on FSDS-R & 0.58 & 0.14 & 4.17 & $<.001$ \\
\hline Indirect effect of BSMAS on FSDS-R & Effect & Boot $S E$ & Boot LLCI & Boot ULCI \\
\hline Total & 0.65 & 0.16 & 0.43 & 1.01 \\
\hline URCS & 0.38 & 0.10 & 0.24 & .62 \\
\hline MSPSS & 0.26 & 0.08 & 0.15 & .46 \\
\hline
\end{tabular}

Note. Age, husband's education, baseline values of depression, anxiety, FSFI, and FSDS-R were adjusted for both Models A and B. MSPSS: Multidimensional Scale of Perceived Social Support; BSMAS: Bergen Social Media Addiction Scale; FSFI: Female Sexual Function Index; FSDS-R: Female Sexual Distress Scale - Revised; URCS: Unidimensional Relationship Closeness Scale; Boot SE: bootstrapping standard error; Boot LLCI: bootstrapping lower limit of confidence interval; Boot ULCI: bootstrapping upper limit of confidence interval.

${ }^{\mathrm{a}}$ Mediators were assessed at baseline.

percentage of the variance of the relationship between the social media use and sexual function $(31.1 \%)$ and sexual distress $(45.6 \%)$. Therefore, the results of the study confirmed that social media addiction not only directly contributed to female sexual dysfunction but also indirectly through the reduction of the amount of intimacy between couples and perceived social support.

\section{Limitations}

The main limitation of this study was the lack of access to the partners of the female participants. Therefore, data concerning male psychological and sexual characteristics were not collected. Given the fact that marital relationships are bilateral and affected by both the woman and her partner, and that male psychological and sexual characteristics affect female sexual function, future studies on couples and dyads are suggested. It should also be noted that the nature of selfreport data is subject to well-known biases (such as memory recall and social desirability).

\section{CONCLUSIONS}

This study demonstrated that social media addiction negatively affected women's sexual function. Accordingly, attention to the role of social media is essential in improving intimacy and supporting couples. Sexual counseling should be considered an essential element for assessing individual behaviors in the context of social media use, particularly when it is excessive or problematic. In addition, behavioral interventions to help improve the behavior of individuals in their use of social media should be addressed in the treatment plan involving women who have a sexual dysfunction.

Funding sources: None.

Authors' contribution: ZA and AHP designed the study and wrote the protocol. VI and AHP collected the data and conducted the statistical analysis. MDG and C-YL contributed in editing, interpretation, and revision processes. All authors contributed to and have approved the final version of the manuscript.

Conflict of interest: MDG is the co-developer of the original version of the Bergen Social Media Addiction Scale (BSMAS). All authors report no financial or other relationship relevant to the subject of this paper.

\section{REFERENCES}

American Psychiatric Association. (2013). Diagnostic and statistical manual of mental disorders (5th ed.). Arlington, VA: American Psychiatric Association. 
Anand, A., Brandwood, H. J., \& Jameson Evans, M. (2017). Improving patient involvement in the drug development process: Case study of potential applications from an online peer support network. Clinical Therapeutics, 39(11), 2181-2188. doi:10.1016/j.clinthera.2017.10.004

Andreassen, C. S., Billieux, J., Griffiths, M. D., Kuss, D. J., Demetrovics, Z., Mazzoni, E., \& Pallesen, S. (2016). The relationship between addictive use of social media and video games and symptoms of psychiatric disorders: A large-scale cross-sectional study. Psychology of Addictive Behaviors, 30(2), 252-262. doi:10.1037/adb0000160

Aydın, B., Sarı, S. V., \& Şahin, M. (2018). The effect of social networking on the divorce process. Universal Journal of Psychology, 6(1), 1-8. doi:10.13189/ujp.2018.060101

Azimi Nekoo, E., Burri, A., Ashrafti, F., Fridlund, B., Koenig, H. G., Derogatis, L. R., \& Pakpour, A. H. (2014). Psychometric properties of the Iranian version of the Female Sexual Distress Scale-Revised in Women. Journal of Sexual Medicine, 11(4), 995-1004. doi:10.1111/jsm. 12449

Bányai, F., Zsila, Á., Király, O., Maraz, A., Elekes, Z., Griffiths, M. D., Andreassen, C. S., \& Demetrovics, Z. (2017). Problematic social media use: Results from a large-scale nationally representative adolescent sample. PLoS One, 12(1), e0169839. doi:10.1371/journal.pone.0169839

Barzoki, M. H., Seyedroghani, N., \& Azadarmaki, T. (2013). Sexual dissatisfaction in a sample of married Iranian women. Sexuality \& Culture, 17(2), 244-259. doi:10.1007/s12119012-9149-y

Bridges, A. J., \& Morokoff, P. J. (2011). Sexual media use and relational satisfaction in heterosexual couples. Personal Relationships, 18(4), 562-585. doi:10.1111/j.1475-6811.2010. 01328.x

Burri, A., Rahman, Q., \& Spector, T. (2011). Genetic and environmental risk factors for sexual distress and its association with female sexual dysfunction. Psychological Medicine, 41(11), 2435-2445. doi:10.1017/S0033291711000493

Cooper, A., \& Griffin-Shelley, E. (2002). Introduction. The Internet: The next sexual revolution. New York, NY: BrunnerRoutledge.

Daneback, K., Ross, M. W., \& Månsson, S.-A. (2006). Characteristics and behaviors of sexual compulsives who use the Internet for sexual purposes. Sexual Addiction \& Compulsivity, 13(1), 53-67. doi:10.1080/10720160500529276

DeRogatis, L., Clayton, A., Lewis-D’Agostino, D., Wunderlich, G., \& Fu, Y. (2008). Validation of the Female Sexual Distress Scale-Revised for assessing distress in women with hypoactive sexual desire disorder. Journal of Sexual Medicine, 5(2), 357-364. doi:10.1111/j.1743-6109.2007.00672.x

Dibble, J. L., Levine, T. R., \& Park, H. S. (2012). The Unidimensional Relationship Closeness Scale (URCS): Reliability and validity evidence for a new measure of relationship closeness. Psychological Assessment, 24(3), 565-572. doi:10.1037/ a0026265

Dong, G., \& Potenza, M. N. (2014). A cognitive-behavioral model of Internet gaming disorder: Theoretical underpinnings and clinical implications. Journal of Psychiatric Research, 58, 7-11. doi:10.1016/j.jpsychires.2014.07.005

Eichenberg, C., Huss, J., \& Küsel, C. (2017). From online dating to online divorce: An overview of couple and family relationships shaped through digital media. Contemporary Family Therapy, 39(4), 249-260. doi:10.1007/s10591-017-9434-x
Fakhri, A., Pakpour, A. H., Burri, A., Morshedi, H., \& Zeidi, I. M. (2012). The Female Sexual Function Index: Translation and validation of an Iranian version. Journal of Sexual Medicine, 9(2), 514-523. doi:10.1111/j.1743-6109.2011.02553.x

Felmlee, D. H. (2001). No couple is an island: A social network perspective on dyadic stability. Social Forces, 79(4), 12591287. doi:10.1353/sof.2001.0039

Financial Tribune. (2018, February 6). Latest data on Iran: Surge in social media use Financial Tribune. First Iranian English Economic Daily. Retrieved March 13, 2019, from https:// financialtribune.com/articles/sci-tech/81536/latest-data-on-iransurge-in-social-media-use

Goodson, P., McCormick, D., \& Evans, A. (2001). Searching for sexually explicit materials on the Internet: An exploratory study of college students' behavior and attitudes. Archives of Sexual Behavior, 30(2), 101-118. doi:10.1023/A:1002724116437

Griffiths, M. D. (2000). Internet addiction - Time to be taken seriously? Addiction Research, 8(5), 413-418. doi:10.3109/ 16066350009005587

Griffiths, M. D. (2017). Commentary: Development and validation of a self-reported questionnaire for measuring Internet search dependence. Frontiers of Public Health, 5, 95. doi:10.3389/ fpubh.2017.00095

Hayes, A. F. (2013). Introduction to mediation, moderation, and conditional process analysis: A regression-based approach. New York, NY: The Guilford Press.

He, Q., Turel, O., \& Bechara, A. (2017). Brain anatomy alterations associated with social networking site (SNS) addiction. Scientific Reports, 7(1), 45064. doi:10.1038/srep45064

Heiman, J. R., Long, J. S., Smith, S. N., Fisher, W. A., Sand, M. S., \& Rosen, R. C. (2011). Sexual satisfaction and relationship happiness in midlife and older couples in five countries. Archives of Sexual Behavior, 40(4), 741-753. doi:10.1007/ s10508-010-9703-3

Hertlein, K. M. (2012). Digital dwelling: Technology in couple and family relationships. Family Relations, 61(3), 374-387. doi:10.1111/j.1741-3729.2012.00702.x

International Telecommunication Union. (2017). ICT facts and figures 2017. Retrieved March 13, 2019, from https://www. itu.int/en/ITU-D/Statistics/Documents/facts/ICTFactsFigures 2017.pdf

Internet World Stats. (2018). Iran Internet usage, broadband and telecommunications reports. Middle East Telecommunications Reports. Retrieved March 13, 2019, from https://www.internet worldstats.com/me/ir.htm

Johannes, C. B., Clayton, A. H., Odom, D. M., Rosen, R. C., Russo, P. A., Shifren, J. L., \& Monz, B. U. (2009). Distressing sexual problems in United States women revisited: Prevalence after accounting for depression. Journal of Clinical Psychiatry, 70(12), 1698-1706. doi:10.4088/JCP.09m05390gry

Johnson, S. D., Phelps, D. L., \& Cottler, L. B. (2004). The association of sexual dysfunction and substance use among a community epidemiological sample. Archives of Sexual Behavior, 33(1), 55-63. doi:10.1023/B:ASEB.0000007462. $97961.5 \mathrm{a}$

Krull, J. L., \& Mackinnon, D. P. (1999). Multilevel mediation modeling in group based intervention studies. Evaluation Review, 23(4), 418-444. doi:10.1177/0193841X9902300404

Lin, C.-Y., Broström, A., Nilsen, P., Griffiths, M. D., \& Pakpour, A. H. (2017a). Psychometric validation of the Persian Bergen Social Media Addiction Scale using classic test theory and 
Rasch models. Journal of Behavioral Addictions, 6(4), 620-629. doi:10.1556/2006.6.2017.071

Lin, C.-Y., Burri, A., Fridlund, B., \& Pakpour, A. H. (2017b). Female sexual function mediates the effects of medication adherence on quality of life in people with epilepsy. Epilepsy \& Behavior, 67, 60-65. doi:10.1016/j.yebeh.2016.12.012

Lin, C.-Y., Ganji, M., Pontes, H. M., Imani, V., Broström, A., Griffiths, M. D., \& Pakpour, A. H. (2018). Psychometric evaluation of the Persian Internet Disorder Scale among adolescents. Journal of Behavioral Addictions, 7(3), 665-675. doi:10.1556/2006.7.2018.88

Lin, C.-Y., Oveisi, S., Burri, A., \& Pakpour, A. H. (2017c). Theory of planned behavior including self-stigma and perceived barriers explain help-seeking behavior for sexual problems in Iranian women suffering from epilepsy. Epilepsy \& Behavior, 68, 123-128. doi:10.1016/j.yebeh.2017.01.010

Lin, C.-Y., \& Pakpour, A. H. (2017). Using Hospital Anxiety and Depression Scale (HADS) on patients with epilepsy: Confirmatory factor analysis and Rasch models. Seizure, 45, 42-46. doi:10.1016/j.seizure.2016.11.019

Luo, S., \& Tuney, S. (2015). Can texting be used to improve romantic relationships? - The effects of sending positive text messages on relationship satisfaction. Computers in Human Behavior, 49, 670-678. doi:10.1016/j.chb.2014.11.035

Masthi, N. R., Pruthvi, S., \& Phaneendra, M. (2018). A comparative study on social media usage and health status among students studying in pre-university colleges of urban Bengaluru. Indian Journal of Community Medicine, 43(3), 180-184. doi:10.4103/ijcm.IJCM_285_17

McDaniel, B. T., \& Coyne, S. M. (2016). "Technoference": The interference of technology in couple relationships and implications for women's personal and relational well-being. Psychology of Popular Media Culture, 5(1), 85-98. doi:10.1037/ ppm0000065

McNulty, J. K., Wenner, C. A., \& Fisher, T. D. (2016). Longitudinal associations among relationship satisfaction, sexual satisfaction, and frequency of sex in early marriage. Archives of Sexual Behavior, 45(1), 85-97. doi:10.1007/s10508-014-0444-6

Montazeri, A., Vahdaninia, M., Ebrahimi, M., \& Jarvandi, S. (2003). The Hospital Anxiety and Depression Scale (HADS): Translation and validation study of the Iranian version. Health \& Quality of Life Outcomes, 1(1), 14. doi:10.1186/1477-7525-1-14

Muusses, L. D., Kerkhof, P., \& Finkenauer, C. (2015). Internet pornography and relationship quality: A longitudinal study of within and between partner effects of adjustment, sexual satisfaction and sexually explicit Internet material among newly-weds. Computers in Human Behavior, 45, 77-84. doi:10.1016/j.chb.2014.11.077

Olmstead, S. B., Negash, S., Pasley, K., \& Fincham, F. D. (2013). Emerging adults' expectations for pornography use in the context of future committed romantic relationships: A qualitative study. Archives of Sexual Behavior, 42(4), 625-635. doi:10.1007/s10508-012-9986-7

Pakpour, A. H., Yekaninejad, M. S., Pallich, G., \& Burri, A. (2015). Using ecological momentary assessment to investigate short-term variations in sexual functioning in a sample of perimenopausal women from Iran. PLoS One, 10(2), e 0117299. doi:10.1371/journal.pone.0117299
Pakpour, A. H., Zeidi, I. M., Yekaninejad, M. S., \& Burri, A. (2014). Validation of a translated and culturally adapted Iranian version of the International Index of Erectile Function. Journal of Sex \& Marital Therapy, 40(6), 541-551. doi:10.1080/ 0092623X.2013.788110

Peleg, O. (2008). The relation between differentiation of self and marital satisfaction: What can be learned from married people over the course of life? American Journal of Family Therapy, 36(5), 388-401. doi:10.1080/01926180701804634

Roberts, J. A., \& David, M. E. (2016). My life has become a major distraction from my cell phone: Partner phubbing and relationship satisfaction among romantic partners. Computers in $\mathrm{Hu}$ man Behavior, 54, 134-141. doi:10.1016/j.chb.2015.07.058

Rosen, R., Brown, C., Heiman, J., Leiblum, S., Meston, C., Shabsigh, R., Ferguson, D., \& D'Agostino, R., Jr. (2000). The Female Sexual Function Index (FSFI): A multidimensional self-report instrument for the assessment of female sexual function. Journal of Sex \& Marital Therapy, 26(2), 191-208. doi:10.1080/009262300278597

Salimi, A., Joukar, B., \& Nikpour, R. (2009). Internet and communication: Perceived social support and loneliness as antecedent variables. Psychological Studies, 5(3), 81-102.

Schmiedeberg, C., \& Schroder, J. (2016). Does sexual satisfaction change with relationship duration? Archives of Sexual Behavior, 45(1), 99-107. doi:10.1007/s10508-015-0587-0

Serati, M., Salvatore, S., Siesto, G., Cattoni, E., Zanirato, M., Khullar, V., Cromi, A., Ghezzi, F., \& Bolis, P. (2010). Female sexual function during pregnancy and after childbirth. Journal of Sexual Medicine, 7(8), 2782-2790. doi:10.1111/j.17436109.2010.01893.x

Sinha, S., \& Mukerjee, N. (1990). Marital adjustment and personal space orientation. Journal of Social Psychology, 130(5), 633-639. doi:10.1080/00224545.1990.9922955

StatCounter. (2018). Social media stats in Islamic Republic of Iran. Retrieved March 13, 2019, from http://gs.statcounter.com/ social-media-stats/all/iran

Statista. (2018). Number of social network users worldwide from 2010 to 2021 (in billions). Retrieved March 13, 2019, from https:/www.statista.com/statistics/278414/number-of-worldwide-social-network-users/

Whitty, M. T. (2008). Liberating or debilitating? An examination of romantic relationships, sexual relationships and friendships on the net. Computers in Human Behavior, 24(5), 1837-1850. doi:10.1016/j.chb.2008.02.009

Yao, M. Z., \& Zhong, Z.-J. (2014). Loneliness, social contacts and Internet addiction: A cross-lagged panel study. Computers in Human Behavior, 30, 164-170. doi:10.1016/j.chb.2013.08.007

Zheng, L., \& Zheng, Y. (2014). Online sexual activity in mainland China: Relationship to sexual sensation seeking and sociosexuality. Computers in Human Behavior, 36, 323-329. doi:10.1016/j.chb.2014.03.062

Zigmond, A. S., \& Snaith, R. P. (1983). The Hospital Anxiety and Depression Scale. Acta Psychiatrica Scandinavica, 67(6), 361-370. doi:10.1111/j.1600-0447.1983.tb09716.x

Zimet, G. D., Dahlem, N. W., Zimet, S. G., \& Farley, G. K. (1988). The Multidimensional Scale of Perceived Social Support. Journal of Personality Assessment, 52(1), 30-41. doi:10.1207/ s15327752jpa5201_2 